\title{
Freiheitsrechte und Rauchverbote
}

Rainer M. Kaelin

Das Karlsruher Gericht entschied am 30. Juli 2008, dass die Passivrauchschutzgesetze von BadenWürttemberg [1] und Berlin [2] verfassungswidrig seien. Es gab Klägern Recht, die beanstandeten, dass sie seit der Einführung der Rauchverbote Beeinträchtigungen einzustecken hätten, da ihre Betriebe dadurch unverhältnismässig stark betroffen würden. Dieses Urteil wurde als Sieg der Freiheitsrechte über die in europäischen Ländern eingeführten Rauchverbote dargestellt. Die Analyse des Urteils führt zu einem anderen Schluss.

\section{Ausgangslage}

Zwei Kläger waren Inhaber einer Berliner Eckkneipe und eines ähnlichen Betriebs in BadenWürttemberg, die vor allem Getränke anbieten und primär Quartierbewohner aus der Umgebung als Kunden haben. Die neuen Ländergesetze

\section{Das Rauchverbot in Gaststätten zugunsten der Nicht- raucher ist keine unverhältnismässige Freiheits- einschränkung für Raucher}

Für die Durchsicht des Manuskripts danke ich Hanspeter Kuhn, Fürsprecher, Stv. Generalsekretär FMH. sehen vor, dass alle Gasträume grundsätzlich rauchfrei sind; der Inhaber darf aber Raucherräume einrichten, in denen keine Speisen angeboten werden. Die Kleinbetriebe, so die Argumentation der Kläger, würden nun benachteiligt, da ihre rauchenden Kunden in grössere Betriebe abwanderten, die solche Raucherräume einrichten könnten, was für sie selbst unmöglich sei. Dies beeinträchtige die freie Berufsausübung.

Dritter Kläger war der Inhaber einer Diskothek: Er wehrte sich dagegen, dass ihm das Baden-Württembergische Gesetz einen Raucherraum verweigere, obwohl die Einrichtung solcher Räume für Gaststätten erlaubt sei. Sein Betrieb werde nicht gleichbehandelt wie Tanzflächen von Festzelten, die vom Rauchverbot ausgenommen seien.

\section{Das Urteil}

Das Gericht stellte fest, dass der Grundsatz, wonach alle vor dem Gesetz gleich seien, in beiden Fällen nicht respektiert werde. Dennoch erklär- ten die Richter die Gesetze nicht für ungültig, sondern setzten den Ländern eine Frist für die notwendigen Revisionen. Bis zu deren Realisierung werden vorläufige Regelungen eingeführt: Eckkneipen dürfen sich als Raucherlokal deklarieren, falls keine Speisen angeboten werden und das Lokal gut sichtbar seine angehenden Kunden auf die Passivrauchgefährdung aufmerksam macht. Dem Inhaber der Diskothek wird ein Raucherraum zugestanden; dieser darf weder eine Tanzfläche aufweisen, noch dürfen darin Speisen angeboten werden.

\section{Die Urteilsbegründung}

Das Gericht hält fest, dass der Gesundheitsschutz von Bevölkerung und Angestellten höheres Rechtsgut sei als Beschränkungen der Betriebsinhaber. Dies entspricht der Verfassung, die mit der von Deutschland ratifizierten internationalen Tabakrahmenkonvention der WHO konform ist. Die Richter zitieren die Übereinstimmung der wissenschaftlichen Daten, was ihnen erlaubt, Prof. Scherrers [3] Expertenmeinung zu ignorieren. Der Münchner Pharmakologe/Toxikologe hatte geltend gemacht, Gesundheitsgefahren durch Passivrauchbelastung seien relativ gering und teilweise nicht nachweisbar, weshalb eine Nullexposition weder praktikabel noch notwendig sei.

Das Rauchverbot in Gaststätten zugunsten der Nichtraucher ist gemäss richterlicher Begründung keine unverhältnismässige Freiheitseinschränkung für Raucher «zumal (diese) die Gaststätte zeitweilig verlassen können». Das Verbot ist tauglich und erforderlich, da keine andere Massnahme gleich wirksam ist. Nicht die Regel behandelt die Betriebe ungleich, sondern die Ausnahmen. In ihren Vorschlägen weisen die Richter darauf hin, dass eine strikte Regelung vom Standpunkt der Verfassung nicht zu beanstanden sei.

\section{Bedeutung für die Schweiz?}

Diese Begründungen entsprechen denen des Bundesgerichtes [4], das die Genfer Volksinitiative (die keinen Raucherraum vorsah) als verfassungskonform beurteilte. Dabei hat es sich ebenfalls auf die wissenschaftliche Datenlage und die Tabakrahmenkonvention der WHO abgestützt. Da die Kläger von beschränkten Freiheitsrechten 
ausgingen, äusserte es sich auch bei dieser Abwägung zugunsten der öffentlichen Gesundheit [5]. Zusammenfassend dürfte man also erwarten, dass auch die Schweiz schliesslich ein Bundesgesetz in Kraft setzen wird, in dem nicht die Ausnahmen die Anwendung des Gesetzes verunmöglichen [6, 7]. Lex brevis esto: Kurz soll das Gesetz sein. Und das Recht auf rauchfreie Luft für jedermann ausdrücken.

\section{Literatur}

1 Landesnichtraucherschutzgesetz von BadenWürttemberg vom 25.7.2007. Gesetzesblatt für Baden-Württemberg. Seite 337.

2 Berliner Gesetz zum Schutz vor den Gefahren des Passivrauchens in der Öffentlichkeit vom 16.11.2007. Nichtraucherschutzgesetz, Gesetzund Verordnungsblatt für Berlin. Seite 578 .

3 Prof. Gerhard Scherrer leitet seit Jahren das von der Zigarettenindustrie bezahlte Analytisch-Biologische Forschungslabor in München.

4 Bundesgerichtsentscheid 133 I 110 vom 28.3.2007 (www.bger.ch). Auszug aus dem Entscheid im Falle Slatkine und Pétroz gegen den Grossen Rat des Kantons Genf: «Die Schädlichkeit des Passivrauches ist durch genügend wissenschaftliche Studien bezeugt, so dass dies als dem heutigen Stand der Wissenschaft entsprechend betrachtet werden kann und nicht nur [...] als eine vorübergehende Mode oder als ein einfacher Ausdruck des 〈politically correct»» (Übersetzung des Autors).
Dies widerspricht klar dem Gutachten von Prof. Andreas Auer, das er im Oktober 2005 zur Genfer Volksinitiative zum Passivrauchschutz veröffentlichte. Es trägt den Titel «Le droit face à la 〈political correctness»» und war auf Auftrag von der Tabakindustrie JT international (Camel, Mild Seven, Winston) entstanden. Der damalige Rektor der Universität Prof. André Hurst kritisierte den Verfassungsrechtler in einem offenen Brief, sich von der Industrie bezahlen zu lassen. Es wurde auch von anderer Seite öffentlich darauf hingewiesen, dass Auer sich auf die im BMJ veröffentlichte Studie über Passivrauch abgestützt hatte, die von der Tabakindustrie bezahlt worden war. Siehe den Bericht von Denis Masmejan vom 2.11.2008 «Le Temps» (www.letemps.ch).

5 Bundesgerichtsentscheid 133 I 110 vom 28.3.2007. Erwägung 5 über persönliche Freiheit und Rauchen: «Wenn es zweifelhaft ist, dass Rauchen sich von der persönlichen Freiheit ableiten lässt, dann ist es noch zweifelhafter, dass das verfassungsmässig verankerte Recht die Freiheit schützt, überall und jederzeit rauchen zu dürfen, insbesondere in öffentlichen Räumen.» (Übersetzung des Autors). $\mathrm{Zu}$ den Entwicklungen der Gesetzgebung auf dem Gebiet des Passivrauches in der Schweiz siehe auch Olivier Guillod (Institut Droit et Santé, Universität Neuchâtel) 14. Journée de droit et santé, Editions Weblaw, Berne 2008, Abschnitt III a. L' écran de fumée s'éclaircit, Seite 26.

6 Cortesi A. Chaotische Zustände beim Vollzug des Rauchverbotes. Tages-Anzeiger, 6. September 2008.

7 Schmid A. Chaos mit Rauchverboten. Der Wirrwarr unterschiedlicher Vorschriften irritiert Befürworter und Gegner. NZZ am Sonntag, 9. November 2008. 